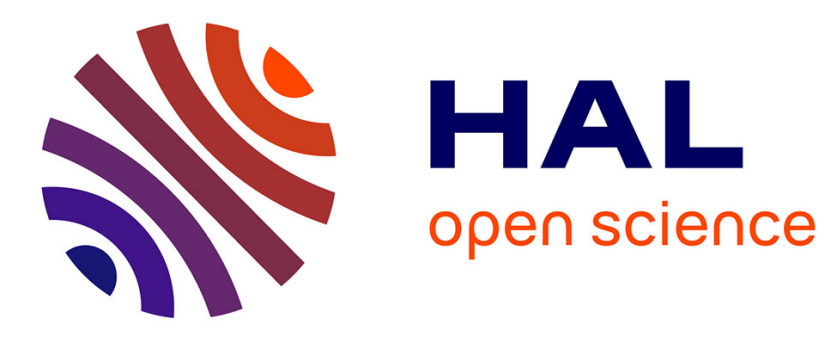

\title{
Practical delay modeling of externally recirculated burned gas fraction for Spark-Ignited engines
}

Delphine Bresch-Pietri, Thomas Leroy, Jonathan Chauvin, Nicolas Petit

\section{To cite this version:}

Delphine Bresch-Pietri, Thomas Leroy, Jonathan Chauvin, Nicolas Petit. Practical delay modeling of externally recirculated burned gas fraction for Spark-Ignited engines. 11th IFAC Workshop on Time-Delay Systems, Feb 2013, Grenoble, France. pp.232-237, 10.3182/20130204-3-FR-4031.00202 . hal-00873571

\section{HAL Id: hal-00873571 \\ https://hal-mines-paristech.archives-ouvertes.fr/hal-00873571}

Submitted on 10 Mar 2015

HAL is a multi-disciplinary open access archive for the deposit and dissemination of scientific research documents, whether they are published or not. The documents may come from teaching and research institutions in France or abroad, or from public or private research centers.
L'archive ouverte pluridisciplinaire HAL, est destinée au dépôt et à la diffusion de documents scientifiques de niveau recherche, publiés ou non, émanant des établissements d'enseignement et de recherche français ou étrangers, des laboratoires publics ou privés. 


\title{
Practical delay modeling of externally recirculated burned gas fraction for Spark-Ignited Engines
}

\author{
D. Bresch-Pietri ${ }^{*}$ T. Leroy ${ }^{* *}$ J. Chauvin ${ }^{* *}$ N. Petit ${ }^{*}$ \\ * MINES ParisTech, Centre Automatique et Systèmes, Unité Mathématiques et \\ Systèmes, 60 Bd St-Michel, 75272 Paris, Cedex 06, France \\ (e-mail : delphine.bresch-pietri@mines-paristech.fr) \\ ** IFP Energies nouvelles, Département Contrôle, Signal et Système, 1 et 4 \\ avenue du Bois-Préau, 92852 Rueil-Malmaison, France
}

\begin{abstract}
This paper studies the low-pressure burned gas recirculation in spark-ignited engines and shows, at the light of supportive experimental results, that a linear delay system permits to capture the dominant effects of the system dynamics. The modeled transport delay is defined by implicit equations stemming from first principles. This model is shown to be sufficiently accurate to replace a sensor that would be difficult and costly to implement on commercial engines.
\end{abstract}

\section{INTRODUCTION AND COMPARISON WITH DIESEL EXHAUST GAS RECIRCULATION}

To prevent the malicious knock phenomenon appearing at high load in downsized Spark-Ignited engines, one of the solutions considered in the automotive industry consists in using exhaust gas recirculation (EGR) through a low-pressure circuit (see Hoepke et al. [2012] or Potteau et al. [2007]). A typical implementation is represented in Fig. 1.

Yet, EGR has some downsides. During tip-outs (defined as a transient mode during which the torque demand is suddenly decreased), the presence of burned gases in the intake manifold and later in the combustion chamber seriously impacts the combustion process and may cause the engine to stall. Further, EGR has strong interactions with simultaneously operating engine controllers such as the regulation of Fuel-to-Air Ratio (FAR) to stoichiometry (see Jankovic and Kolmanovsky [2009]). To detail this point, consider Fig. 3 which summarizes one classic engine control architecture upstream the combustion chamber: airpath control, fuelpath control and ignition path control. To counteract the impact of intake burned gas, a solution would be to modify the feedforward action on the cascaded controllers (fuelpath controller and ignition path controller) based on a real-time estimate $\hat{x}$ of the intake burned gas rate. Nevertheless, obtaining this estimate is not an easy task. First, no real-time sensor of this variable is embedded in any real-world vehicle. The approach that we advocate in this paper is to substitute one such sensor with a model ${ }^{1}$.

For the considered low-pressure gas recirculation circuit, the amount of reintroduced burned gases is controlled by the EGR Valve, an actuator which is located upstream of the compressor. Consequently, the relative long distance between the compressor and the inlet manifold leads to a large transport delay (up to several seconds depending on the engine specifications). Most importantly, this delay depends on the gas flow rate and therefore is time-varying to a large extent.

\footnotetext{
1 Other works (see Caicedo et al. [2012]) investigate the potential of using a cylinder pressure sensor signal. Yet, due to stringent cost constraints, such a sensor is not currently commercially embedded.
}

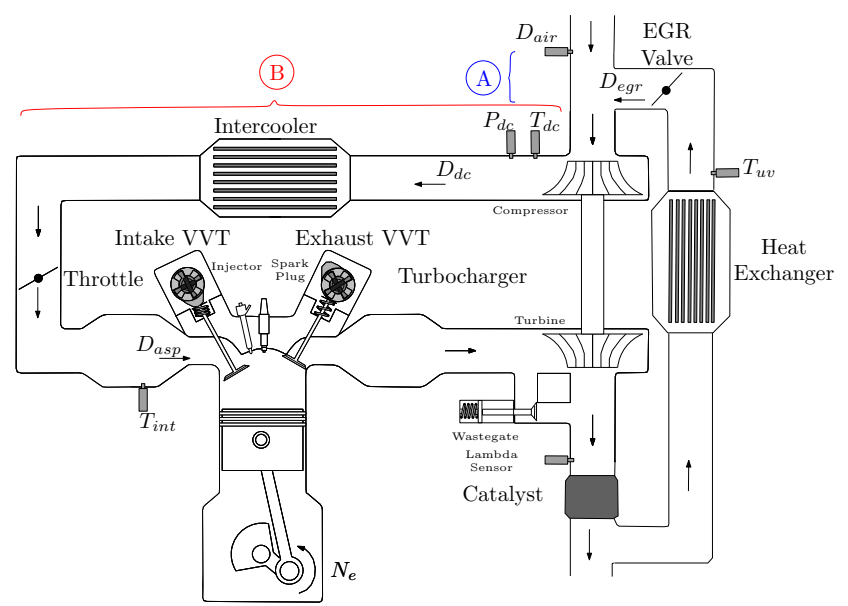

Fig. 1. Scheme of a turbocharged SI engine equipped with direct injection, VVT and a low-pressure EGR loop.

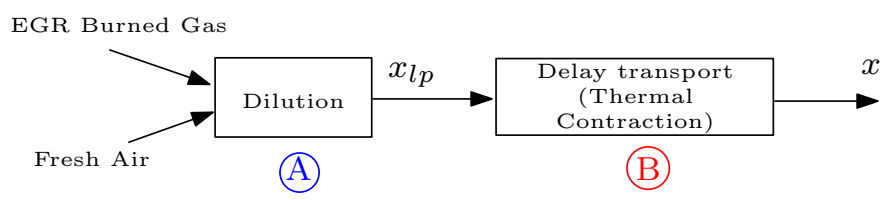

Fig. 2. Scheme of the intake burned gas fraction dynamics.

In the seemingly similar context of automotive Diesel engines, numerous solutions for the discussed control issues have been developed in the last decades (see for example Ammann et al. [2003], Van Nieuwstadt et al. [2000], Zheng et al. [2004] and the references therein). Yet, none of these strategies includes a transport delay model, which as has been discussed is nonnegligible for SI engines. Indeed, on top of using a low-pressure EGR circuit configuration (which substantially increases the transport lag compared to high-pressure configuration studied in Stotsky and Kolmanovsky [2002] or Lauber et al. [2002]), SI engines combustion constraints significantly increase the scale of the delay: (i) first, SI engines operations require a stoichiometric Fuel-to-Air Ratio, which results into a fraction of burned gas close to one in the exhaust line. Consequently, 


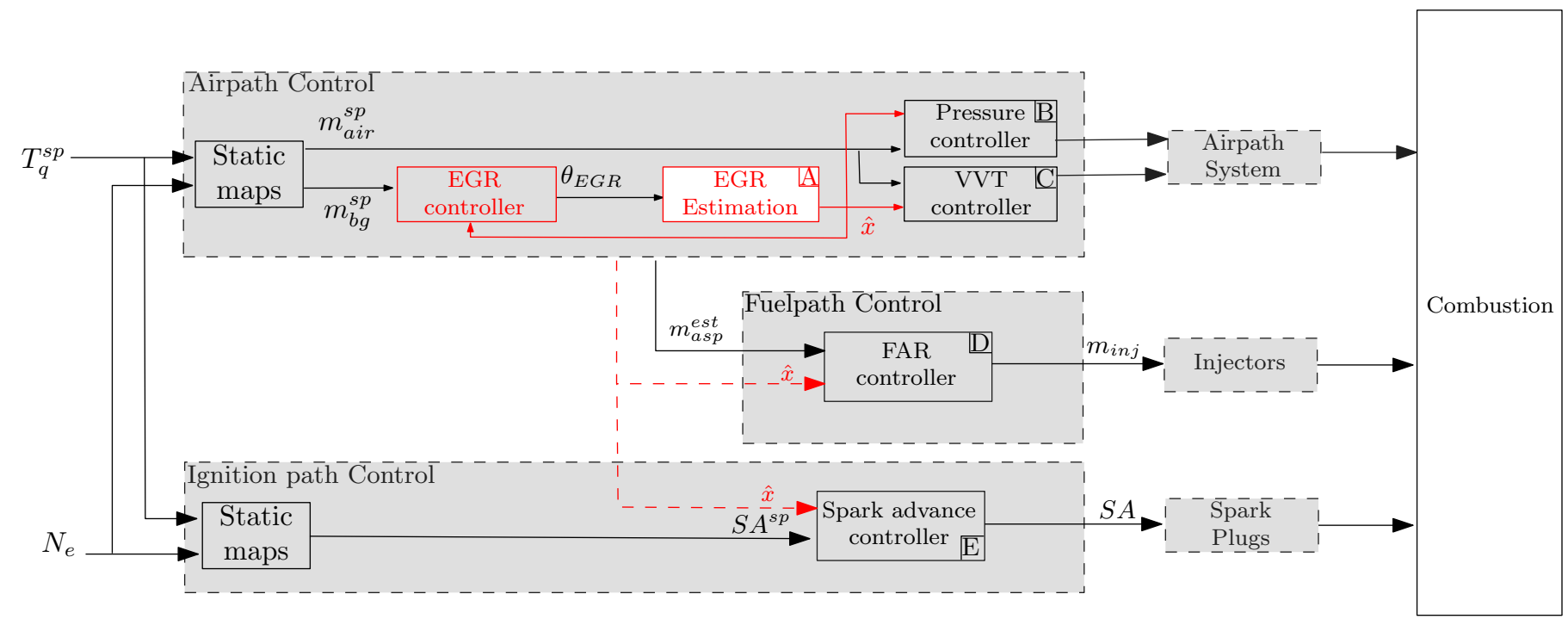

Fig. 3. Classic SI engine control architecture with, in red, the elements relative to EGR. Block A contains the contribution of the paper. Blocks B and C are the low-level pressure and VVT controllers. Block D is the low-level FAR controller. Finally, Block $\mathrm{E}$ is the spark advance controller. $\hat{x}$, an estimate of the intake burned gas fraction, used as an extra feedforward term would bring a relevant mean of controllers coordination and be a source of valuable performances improvements.

Table 1. Acronyms

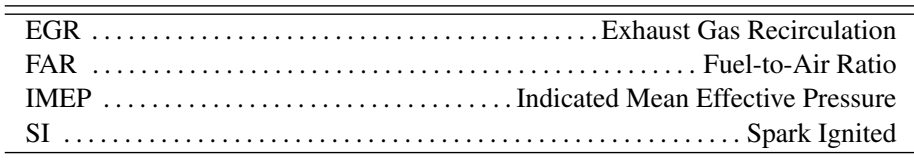

to obtain a given intake fraction of burned gas, the amount of exhaust burned gas to be reintroduced at steady state is substantially lower than the corresponding one for Diesel engines; (ii) besides, on the contrary of Diesel engines, SI engines may operate at intake pressure under atmospheric values (low loads). Then, on this operating range, the steady-state gas flow rates are considerably less important.

For all these reasons, modeling this transport delay is a milestone in the design of controllers for SI engines.

In this paper, a model of the intake burned gas rate is presented, accounting explicitly for transport time-varying delay and its dependency on the history of gas flow rates in a way which compensates for thermal exchanges and induced gas velocity changes. It is then used as a "software" sensor. This estimation is based on a practical delay calculation methodology which is experimentally validated on a test bench. The model along with its practical validation is the main contribution of the article. The estimate is then partially used to coordinate the controllers. Experimental FAR control tests stress the relevance of the estimate.

The paper is organized as follows. In Section II, we present a model of the intake burned gas rate dynamics, under the form of a linear time-varying system with a time-dependent delay output. The practical usage of this model is discussed. Implementation and experimental results are provided in Section III. We conclude by briefly sketching potential directions of work for combustion control improvements.

\section{MODELING}

Consider the airpath of a turbocharged SI engine equipped with intake throttle, wastegate, dual independent VVT actuators and a low-pressure external gas recirculation (EGR) loop as depicted in Fig. 1. Such a setup is usually considered for downsized engines (see Kiencke and Nielsen [2000]). Acronyms and notations used below are listed in Table 1 and 2 respectively.

Formally, the in-cylinder burned gas fraction $x_{c y l}$ is defined as the ratio between the in-cylinder burned gas mass originated from the EGR loop $m_{b g}$ and the total mass of gas in the cylinder volume $m_{\text {asp }}=m_{\text {air }}+m_{b g}$, i.e.

$$
x_{c y l}=\frac{m_{b g}}{m_{\text {air }}+m_{b g}}
$$

From now on, this variable is considered equal to $x$ the intake burned gas fraction ${ }^{2}$.

\subsection{Dilution Dynamics and transport delay}

Defining $x_{l p}$ as the burned gas rate upstream of the compressor, the EGR dynamics can be expressed as

$$
\begin{aligned}
\dot{x}_{l p} & =\alpha\left[-\left(D_{e g r}(t)+D_{a i r}(t)\right) x_{l p}(t)+D_{e g r}(t)\right] \\
x(t) & =x_{l p}(t-\tau(t))
\end{aligned}
$$

where $\tau(t)$, the delay between this ratio and the intake composition, can be implicitly defined by the following integral equation (Plug-Flow assumption for the gas composition along the intake line, see Perry et al. [1984])

$$
\int_{t-\tau(t)}^{t} v_{g a s}(s) d s=L_{P}
$$

where $L_{P}$ is the pipe length from the compressor down to the intake manifold and $v_{\text {gas }}$ stands for the gas speed.

\section{Comments}

Equation (1) is a balance equation on the volume downstream of the EGR valve, using the fact that the EGR circuit is totally filled with burned gas ${ }^{3}$. Depending on engine setups, the thermodynamics constant $\alpha$ appearing in (1) is either measured

2 Actually, this relation depends mainly on the VVT control strategy. We neglect this influence here for sake of clarity.

3 For SI engines, the FAR is regulated to its stoichiometric value (see Heywood [1988]), which results into an exhaust burned gas fraction close to unity. 


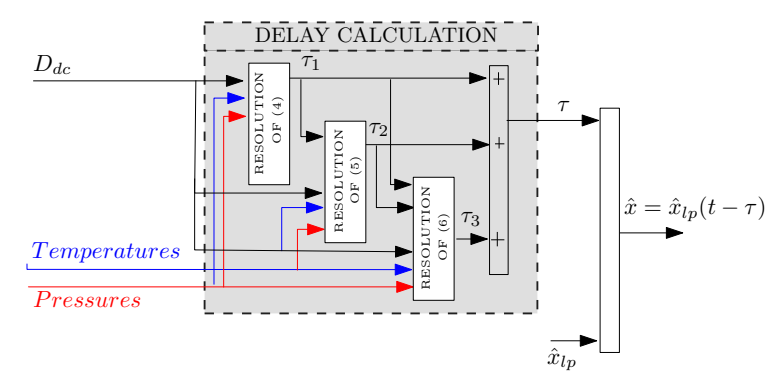

Fig. 4. Scheme of the proposed delay calculation strategy for intake burned gas fraction estimate $x$. The numerical solving of implicit integral equations (4)-(6) can be obtained by sampling and calculating the integrals at increasing values of $\tau_{i}$ starting from 0 , which are real-time compliant calculations.

Table 2. Nomenclature

\begin{tabular}{|lll|}
\hline Symbol & Description & Unit \\
\hline$D_{a i r}$ & Air mass flow rate upstream of the compressor & $\mathrm{kg} / \mathrm{s}$ \\
$D_{e g r}$ & EGR mass flow rate through the EGR valve & $\mathrm{kg} / \mathrm{s}$ \\
$D_{d c}$ & Mass flow rate downstream of the compressor & $\mathrm{kg} / \mathrm{s}$ \\
$D_{a s p}$ & In -cylinder mass flow rate & $\mathrm{kg} / \mathrm{s}$ \\
$v_{g a s}$ & Gas speed & $\mathrm{m} / \mathrm{s}$ \\
$T_{d c}$ & Temperature downstream of the compressor & $\mathrm{K}$ \\
$P_{d c}$ & Pressure downstream of the compressor & $\mathrm{Pa}$ \\
$T_{a t m}$ & Atmospheric temperature & $\mathrm{K}$ \\
$P_{a t m}$ & Atmospheric pressure & $\mathrm{Pa}$ \\
$V_{l p}$ & Volume between the EGR valve and & $\mathrm{m}$ \\
& the compressor & \\
$V_{P}$ & Pipe volume from the compressor to the & $\mathrm{m}$ \\
& intake manifold & \\
$r$ & Specific ideal gas constant & $\mathrm{J} / \mathrm{kg} / \mathrm{K}$ \\
$L_{P}$ & Pipe length from the compressor down & $\mathrm{m}$ \\
& to the intake manifold & \\
$\theta_{e g r}$ & EGR Valve Position & $\%$ \\
$m_{a i r}$ & In-cylinder air mass & $\mathrm{mg} / \mathrm{str}$ \\
$m_{b g}$ & In-cylinder burned gas mass & $\mathrm{mg} / \mathrm{str}$ \\
$m_{a s p}$ & In-cylinder total gas mass & $\mathrm{mg} / \mathrm{str}$ \\
$m_{i n j}$ & Injected mass of fuel & $\mathrm{mg} / \mathrm{str}$ \\
$F A R_{s t}$ & Stoichiometric Fuel-to-Air Ratio & - \\
$x$ & Intake burned gas fraction & - \\
$x_{l p}$ & Burned gas fraction upstream of the compressor & - \\
$x_{c y l}$ & In-cylinder burned gas fraction & - \\
\hline
\end{tabular}

or known. Following the proposed model, which is pictured in Fig. 2, the intake burned gas fraction is the result of a first order dynamics coupled with a transport delay ${ }^{4} 5$.

For sake of clarity, the approach used to model the mass flow rate quantities $\left(D_{\text {egr }}, \ldots\right)$ used through (1)-(3) is not detailed here and given in Appendix. Using the approach presented in Appendix, one can now assume that they are known quantities.

To provide an implementable open-loop estimate of $x$ based on the model (1)-(3), a practical calculation methodology of the delay $\tau$, using only real-time measurements, remains to be developed. This point is now addressed.

\footnotetext{
4 In previous preliminary works (Bresch-Pietri et al. [2012]), another equivalent representation has been proposed, where the dilution has been assumed to take place in the intake manifold. This model is input-delayed, which is formally equivalent in terms of input-output description to the output-delay system proposed here.

5 Alternatively, PDE models can be used to represent more accurately the induced dynamics. However, the induced computational burden discards them from real-time implementations.
}

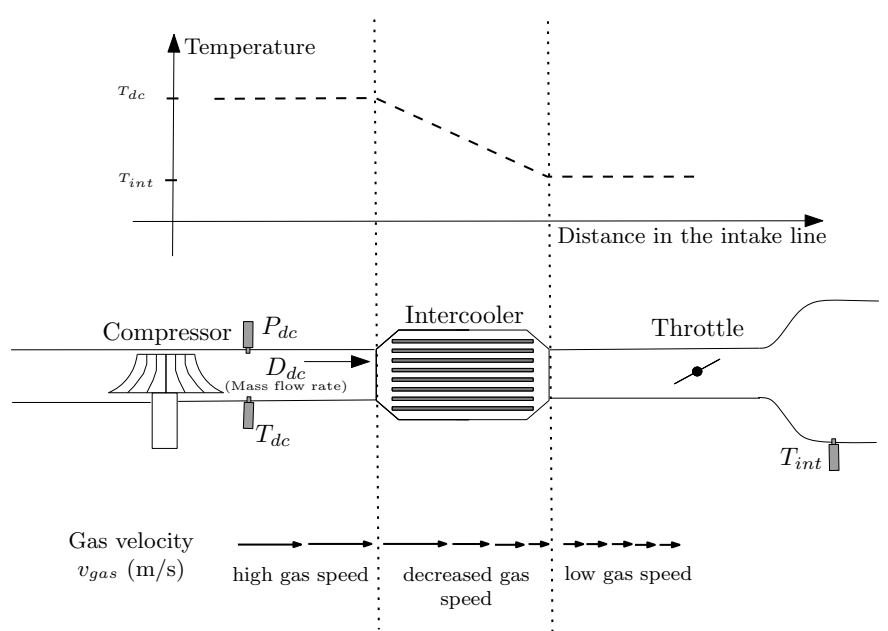

Fig. 5. The intake line is split into three parts to account for the spatial differences of the gas velocity. The temperature decreases, which results into an increase of velocity which is analytically determined by the ideal gas low fed with measurements from temperature and pressure sensors located along the line.

\subsection{Transport delay description}

Equation (3) implicitly determines the delay according to the gas speed along the intake line, which, on top of being a distributed parameter, is not measured in practice. Yet, using the ideal gas law (as is classically done for engine gas flows, e.g. in Heywood [1988]), one can relate this speed to current thermodynamical conditions and mass flow rates, which are measured/modeled. Namely,

$$
\forall t \geq 0, \quad v_{\text {gas }}(t)=\frac{1}{S(t)} \frac{r T(t)}{P(t)}\left[D_{\text {air }}(t)+D_{\text {egr }}(t)\right]
$$

where

- $S$ is the current pipe area

- $T, P$ are the current temperature and pressure values

- $r$ is, as previously, the (common) ideal gas constant of both fresh air and burned gas

In practice, the total mass flow rate under the integral is estimated as $D_{\text {air }}(s)+D_{\text {egr }}(s)=D_{d c}(s)$ (a model of the mass flow rate $D_{d c}$ is provided in (A.2) in Appendix).

A thermal contraction of the gas occurs inside the intake cooler. This results in spatial changes of the gas velocity $v_{\text {gas }}$, pictured in Fig.1. To model this, we split the intake line into three main sections with three respective and cumulative transport delays $\tau_{1}, \tau_{2}$ and $\tau_{3}$ such that $\tau=\tau_{1}+\tau_{2}+\tau_{3}$. This decomposition is also pictured in Fig. 5 .

- downstream of the compressor to the intercooler : in this part, the current pressure and the temperature are measured and one can write

$$
\int_{t-\tau_{1}(t)}^{t} \frac{r T_{d c}}{P_{d c}} D_{d c}(s) d s=V_{1}
$$

with $V_{1}$ the corresponding volume.

- inside the intercooler: considering boundary conditions, the pressure inside the intercooler can reasonably be assumed as constant and equal to the input one $P_{d c}$. Further, we assume that the spatial profile of the inside temperature is affine with respect to the spatial variable, with measured 
boundary conditions $T_{d c}$ and $T_{i n t}{ }^{6}$. Under this assumption, equation (3) can be reformulated on this section as

$$
\begin{aligned}
\int_{t-\tau_{2}(t)-\tau_{1}(t)}^{t-\tau_{1}(t)} \frac{r}{P_{d c}} D_{d c}(s) d s & =S_{2} \int_{0}^{L_{2}} \frac{d x}{T(x)} \\
& =\frac{V_{2}}{T_{i n t}-T_{d c}} \ln \left(\frac{T_{i n t}}{T_{d c}}\right)
\end{aligned}
$$

where $L_{2}, S_{2}$ and $V_{2}$ are the corresponding length, area and volume.

- downstream of the intercooler to the intake manifold: in this section, the temperature can be approximated by the intake manifold temperature, which yields

$$
\int_{t-\tau_{3}(t)-\tau_{2}(t)-\tau_{1}(t)}^{t-\tau_{2}(t)-\tau_{1}(t)} \frac{r T_{i n t}}{P_{d c}} D_{d c}(s) d s=V_{3}
$$

with $V_{3}$ the corresponding volume.

Knowing intermediate volumes $V_{1}, V_{2}$ and $V_{3}$, one can calculate the delay in a very straightforward manner, solving, one after the other, (4), (5) and finally (6). The transport delay is then simply deduced as $\tau(t)=\tau_{1}(t)+\tau_{2}(t)+\tau_{3}(t)$.

The involved numerical solving is based on the observation that the term under the integral is strictly positive and that the integral is then an increasing function of the delay $\tau_{i}$ $(i \in\{1,2,3\})$ appearing in its lower bound. Then, by simply sampling and evaluating the integral at increasing values of $\tau_{i}$ starting from 0 , one can obtain a numerical evaluation of the corresponding delay. All these calculations are on-line compliant $^{7}$.

\subsection{Estimation strategy with practical identification procedure}

An estimation strategy of the model above is summarized on Fig. 4. Real-time measurements of temperatures and pressures serve to determine the value of the delay. These informations are commonly available using (cheap) embedded sensors. Values for physical volumes $\left(V_{l p}, V_{1}, V_{2}\right.$ and $\left.V_{3}\right)$ can be used to calibrate the model.

It is worth noticing that splitting the intake line as has been proposed in the previous section has been motivated mainly by the engine embedded instrumentation and in particular by the availability of temperature (and pressure) sensors. It can be easily adapted to any considered engine. In particular, if no temperature and no pressure sensors are available downstream of the compressor, they can be efficiently approximated by the intake ones at the expense of slight updates of the volumes values in the fit. Indeed, the two pressures are sufficiently close and these equations are of moderate temperature sensitivity. In such a case, the delay can be directly determined by one equation of type (4).

\section{EXPERIMENTAL RESULTS}

The proposed model is now used as a "software" sensor. The obtained estimate is embedded into a real-time control target and employed at test-bench. The experiments aim at validating the model presented in Section III and in particular the delay modeling.

\footnotetext{
6 i.e. $T(x)=\frac{T_{i n t}-T_{d c}}{L_{2}} x+T_{d c}$

7 This approach is directly inspired of Petit et al. [1998] and Zenger and Niemi [2009] for modeling plug flows in networks of pipes problem.
}

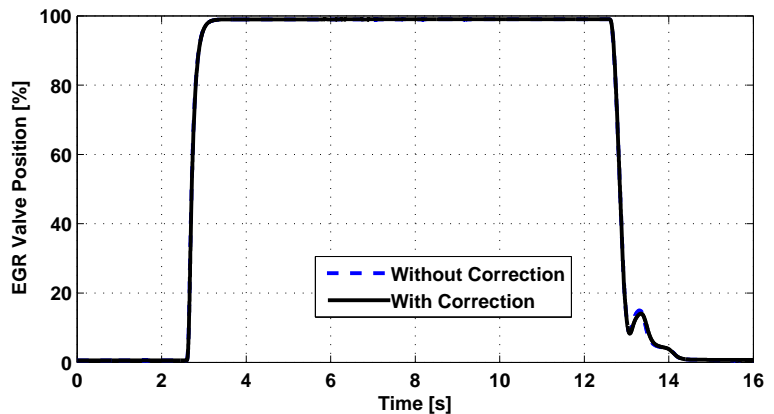

(a) EGR Valve position

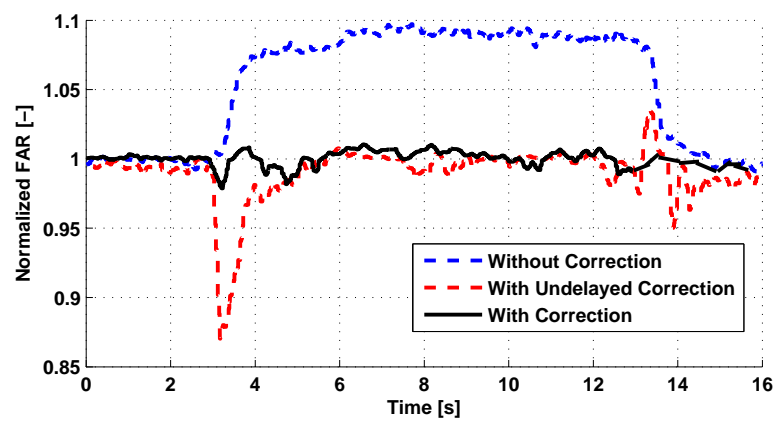

(b) Normalized Fuel-to-Air Ratio

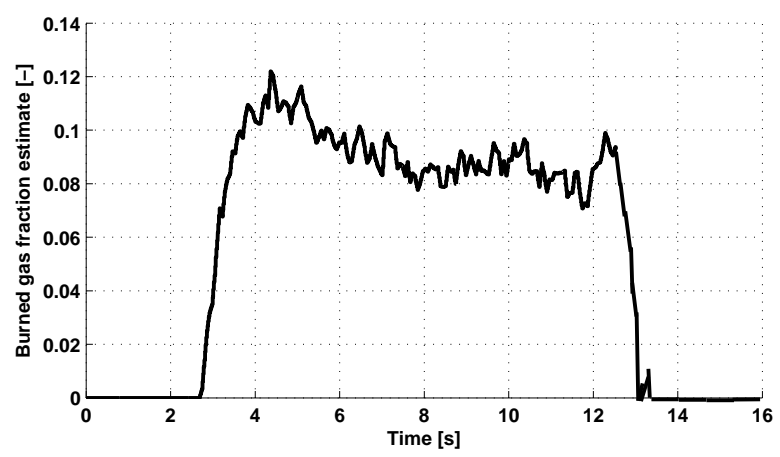

(c) Burned qgas fraction estimate

Fig. 6. Experimental results for constant engine speed $\left(N_{e}=\right.$ $2000 \mathrm{rpm})$ and torque request $(I M E P=8 \mathrm{bar})$. The EGR valve position is pictured in (a). Blue dotted curve : gas composition transient without estimation. Black curve : gas composition transient with estimation and feedforward correction.

\subsection{Experimental setup and indirect validation methodology from FAR measurements}

The engine under consideration is a $1.8 \mathrm{~L}$ four cylinder SI engine with direct injection (see Le Solliec et al. [2006] for details). The airpath consists of a turbocharger controller with a waste gate, an intake throttle, an intercooler and a low-pressure exhaust gas recirculation loop. This engine setup is consistent with the scheme reported in Fig. 1.

To validate the proposed estimation strategy, as no real-time information of the intake burned gas fraction is available for this engine, we focus on the open-loop response of the FAR. This quantity has to be regulated to the unity to maximize the efficiency of post-treatment devices. Usually, this control is realized with the injection path ${ }^{8}$, using the measurements of a dedicated sensor located downstream of the turbine.

\footnotetext{
8 the airpath being then dedicated to meet torque requests.
} 
Here, the FAR is simply controlled by a feedforward strategy on the mass of fuel injected in the cylinder, namely

$$
m_{\text {inj }}=F A R_{s t} m_{\text {air }}
$$

The additional feedback term that is usually used is purposely omitted.

When no burned gas is recirculated, the in-cylinder air mass is accurately estimated with the model presented in Appendix (see Leroy et al. [2009]), i.e. $m_{\text {air }}=m_{\text {asp }}$. When burned gas are reintroduced, one can formally write $m_{\text {air }}=m_{a s p}-m_{b g}=$ $m_{\text {asp }}(1-x)$ and, consequently, estimate the in-cylinder air mass as $m_{\text {as }}(1-\hat{x})$ where $\hat{x}$ is the intake burned gas fraction estimate provided by the proposed model.

With this setup, it is possible to qualitatively relate the FAR variations to the intake burned gas fraction. Indeed, if the estimation is accurate, the normalized FAR remains close to unity and, in turn, one then obtains an indirect validation of the intake burned gas rate estimation. Any offset reveals a steady-state estimation error while any temporary undershoot (or overshoot) reveals a mis-estimation of the delay.

\subsection{First validation : variation of the amount of reintroduced EGR (constant delay)}

The first scenario under consideration here is a variation of the amount of reintroduced burned gas for a given operating point : constant engine speed $N_{e}=2000 \mathrm{rpm}$ for a requested torque of 12.5 bar. This scenario is of particular interest for validation as the intake mixture composition is the only varying variable.

Fig.6(c) pictures the intake burned gas fraction estimates corresponding to the EGR valve variations pictured in (a). The corresponding delay is constant and simply not reported.

\section{With burned gas feedforward correction, i.e. considering} $m_{\text {air }}=(1-\hat{x}) m_{\text {asp }}$

The corresponding normalized FAR evolution is pictured in black, in Fig.6(b). One can easily observe that the normalized FAR remains satisfactorily close to the unity. This behavior reveals a good fit between the real intake manifold burned gas rate and the estimate one provided in Fig.6(c).

For sake of comparisons, the FAR response with a burned gas fraction estimate computed neglecting the delay is also provided (red dotted curves). Neglecting the delay leads to a transient overestimation of the burned gas fraction and, consequently, to a significant FAR undershoot. This stresses the importance of the delay into the burned gas rate dynamics and the relevance of the proposed model.

Without burned gas correction, i.e. considering $m_{\text {air }}=m_{\text {as }}$ In that case, as the in-cylinder mass air is overestimated, the injected mass of fuel turns to be too large. This results into a deviation of the normalized FAR up to 1.09 (blue dotted curve in Fig.6). A feedback control would reasonably eliminate this offset, but, as the obtained FAR measurement is delayed (see Lauber et al. [2011], Bresch-Pietri et al. [2010] for a FAR dynamics details), an important overshoot would still be present.

\subsection{Second validation : torque transients (varying delay)}

The second scenario under consideration is a torque transient requested by the driver, a step from 6 bar to 12.5 bar. This tipin is a typical driving situation case study, which defines an increase in the in-cylinder air mass set point and consequently on the total gas flow rate. Then, both dilution dynamics (1) and the delay are varying.

Further, this also implies a variation of the requested amount of reintroduced burned gas, as the initial operating point is low loaded and does not require any EGR. Without dedicated control structure, we simply consider here the EGR valve position as either fully closed or fully opened. Its variations are pictured in Fig. 7(c).

The corresponding calculated delay is given in Fig. 7(d). As the total mass flow rate increases during the transient, the delay decreases, as expected.

Finally, as in the previous scenario, the FAR remains close to the unity. This validates the burned gas fraction estimate variations depicted in Fig. 7(b).

\section{CONCLUSION AND PERSPECTIVES}

This paper has shown that it is possible to accurately represent the low-pressure burned gas recirculation for Spark Ignited engines as a first order linear dynamics with a time-varying delay. The value of the delay is determined by an implicit integral relation in which data from commonly available sensors (temperatures, pressures) come into play through the ideal gas law.

This model has been experimentally validated by experiences conducted during transients. This result opens new perspectives in term of control applications : coordination of low-level controllers, advanced feedforward compensation,... Yet, because the delay is varying, new techniques are required, especially if one wishes to take advantage of the known source of delay variability.

\section{REFERENCES}

M. Ammann, N. P. Fekete, L. Guzzella, and A. H. Glattfelder. Model-based control of the VGT and EGR in a turbocharged common-rail Diesel engine: theory and passenger car implementation. SAE transactions, 112(3):527-538, 2003.

D. Bresch-Pietri, J. Chauvin, and N. Petit. Adaptive backstepping controller for uncertain systems with unknown input time-delay. application to SI engines. In Proc. of the Conference on Decision and Control, 2010.

D. Bresch-Pietri, T. Leroy, J. Chauvin, and N. Petit. Predictionbased trajectory tracking of external gas recirculation for turbocharged si engines. In Proc. of the American Control Conference, 2012. To appear.

M. A. R. Caicedo, E. Witrant, O. Sename, P. Higelin, et al. A high gain observer for enclosed mass estimation in a spark ignited engine. In Proceedings of the 2012 American Control Conference, 2012.

J. B. Heywood. Internal combustion engine fundamentals. McGraw-Hill New York, 1988.

B. Hoepke, S. Jannsen, E. Kasseris, and W. K. Cheng. EGR effects on boosted SI engine operation and knock integral correlation. SAE International Journal of Engines, 5(2):547559, 2012.

M. Jankovic and I. Kolmanovsky. Developments in control of time-delay systems for automotive powertrain applications. In Delay Differential Equations, recent advances and new directions, Balachandran, B. and Kalmar-Nagy, T. and Gilsinn D. E., pages 55-92. Springer Science, 2009. 


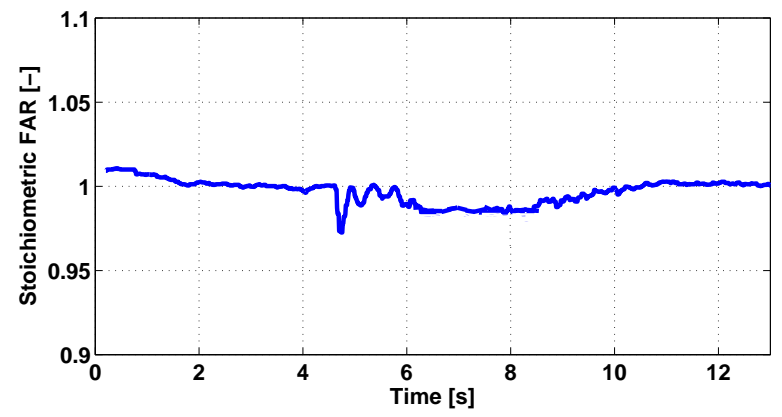

(a) Normalized FAR

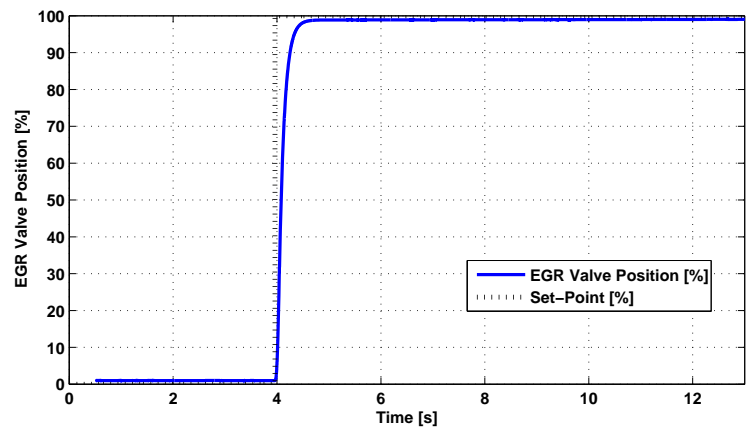

(c) EGR valve position

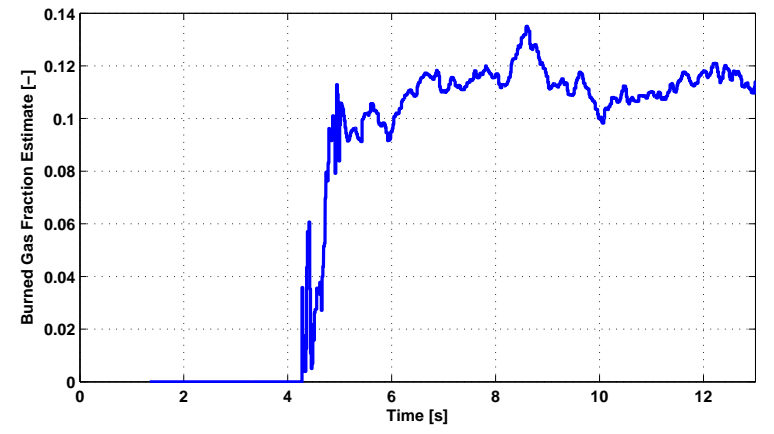

(b) Intake burned gas fraction estimate

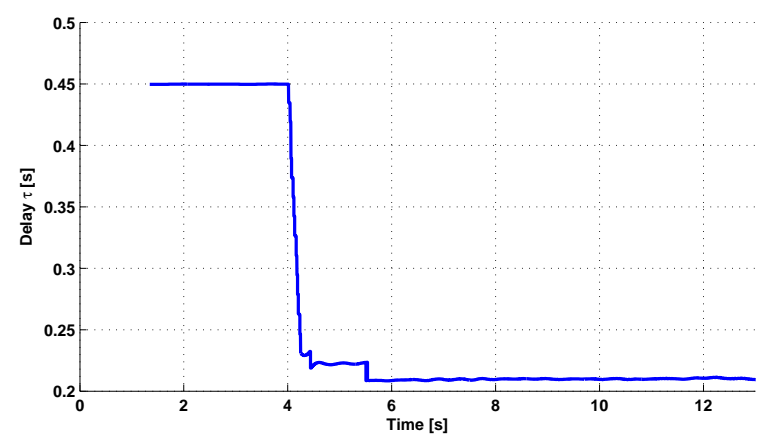

(d) Transport delay

Fig. 7. Experimental results for constant engine speed $\left(N_{e}=2000 \mathrm{rpm}\right)$ and transient torque request (step from $I M E P=6$ bar to 12.5 bar), resulting into a delay variation. The normalized FAR response pictured in (a) uses the intake burned gas fraction estimation pictured in (b), obtained with the on-line estimation of the delay (d).

U. Kiencke and L. Nielsen. Automotive control systems. Springer-Verlag, Berlin, 2000.

J. Lauber, T. M. Guerra, and W. Perruquetti. IC engine: tracking control for an inlet manifold with EGR. SAE Transactions Journal of Passenger Cars: electronic and electrical systems, 20:913-917, 2002.

J. Lauber, T. M. Guerra, and M. Dambrine. Air-fuel ratio control in a gasoline engine. International Journal of Systems Science, 42(2):277-286, 2011.

G. Le Solliec, F. Le Berr, G. Colin, G. Corde, and Y. Chamaillard. Engine control of a downsized spark ignited engine : from simulation to vehicle. In Proc. of ECOSM Conference, 2006.

T. Leroy, J. Chauvin, F. Le Berr, A. Duparchy, and G. Alix. Modeling fresh air charge and residual gas fraction on a dual independant variable valve timing SI engine. $S A E$ International Journal of Engines, 1(1):627-635, 2009.

R. H. Perry, D. W. Green, and J. O. Maloney. Perry's chemical engineers' handbook, volume 7. McGraw-Hill New York, 1984.

N. Petit, Y. Creff, and P. Rouchon. Motion planning for two classes of nonlinear systems with delays depending on the control. In Proceedings of the 37th IEEE Conference on Decision and Control, pages 1007-1011, 1998.

S. Potteau, P. Lutz, S. Leroux, S. Moroz, et al. Cooled EGR for a turbo SI engine to reduce knocking and fuel consumption. In SAE Technical Paper, pages 01-3978, 2007.

A. Stotsky and I. Kolmanovsky. Application of input estimation techniques to charge estimation and control in automotive engines. Control Engineering Practice, 10(12):1371-1383, 2002.

M. J. Van Nieuwstadt, I. V. Kolmanovsky, P. E. Moraal, A. Stefanopoulou, and M. Jankovic. EGR-VGT control schemes: experimental comparison for a high-speed diesel engine. Control Systems Magazine, IEEE, 20(3):63-79, 2000.

K. Zenger and A. J. Niemi. Modelling and control of a class of time-varying continuous flow processes. Journal of Process Control, 19(9):1511-1518, 2009.

M. Zheng, G. T. Reader, and J. G. Hawley. Diesel engine exhaust gas recirculation-a review on advanced and novel concepts. Energy Conversion and Management, 45(6):883900, 2004.

\section{Appendix A. FLOW RATES MODEL}

In-cylinder and downstream compressor mass flow rates We use the model of in-cylinder gas mass presented in Leroy et al. [2009] to define mass flow rates. In this model, $D_{a s p}$ is represented as a function of the engine speed $N_{e}$, the manifold pressure $P_{\text {int }}$ and the intake and exhaust VVT actuators positions. Using the ideal gas law, this flow rate is dynamically related to the flow rates through the throttle and downstream of the compressor as

$$
\begin{aligned}
D_{t h r} & =D_{a s p}\left(N_{e}, P_{i n t}, V V T\right)+\frac{V_{i n t}}{r T_{i n t}} \dot{P}_{\text {int }} \\
D_{d c} & =D_{t h r}+\frac{V_{P}}{r T_{d c}} \dot{P}_{d c}
\end{aligned}
$$

where $r=r_{\text {air }}=r_{b g}$ is the (common) ideal gas constant. The variables used in these two last equations are either known or measured.

EGR mass flow rate Assuming that an intake mass air flow sensor is available on the engine, only the mass flow rate $D_{\text {egr }}$ remains to be expressed. Neglecting the mis-synchronization of the flows signals, we simply write (with a projection operator forcing the flow rate to be zero when the valve is closed)

$$
\hat{D}_{e g r}(t)=\operatorname{Proj}_{\theta_{\text {egr }>0}}\left\{D_{d c}(t)-D_{\text {air }}(t)\right\}
$$

